\title{
EVALUATION OF GEOTHERMAL SYSTEMS IN TWO TECTONIC DEPRESSIONS IN CENTRAL MEXICO
}

Pérez Martínez, ${ }^{1}$; Cardona Benavides A. ${ }^{1}$; Villanueva Estrada R. E. ${ }^{2}$; Rodríguez Díaz A. A. ${ }^{2}$; Rocha Miller R. G. ${ }^{2}$

Bernard Romero R. A. ${ }^{2}$; Rodríguez Salazar M. T. de J. ${ }^{3}$; Castillo López M. ${ }^{1}$ and Guadalupe Rojas J.

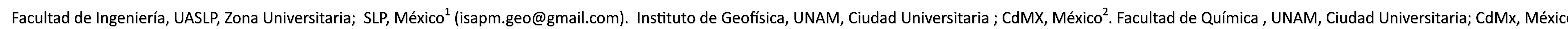

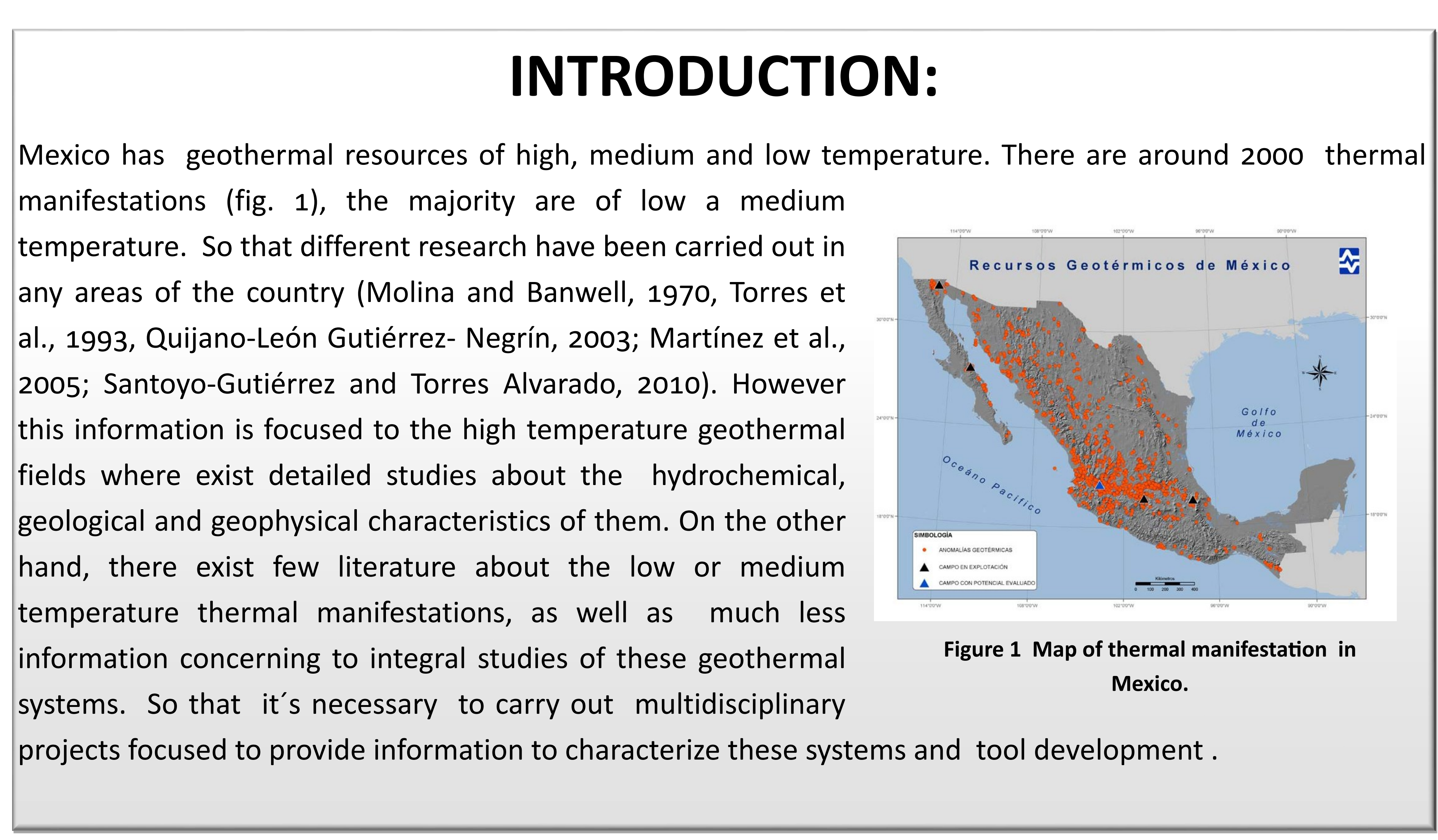

OBJECTIVE:

EVALUATE OF THE GEOTHERMAL SYSTEMS PRESENTS IN THE NORTHEAST AREA OF CHAPALA'S GRABEN (CG), JALISCO STATE AND THE SOUTHERN AREA OF VILLA DE REYES'S GRABEN, GUANAJUATO STATE; ACCORDING TO HYDROGEOCHEMICAL CHAR
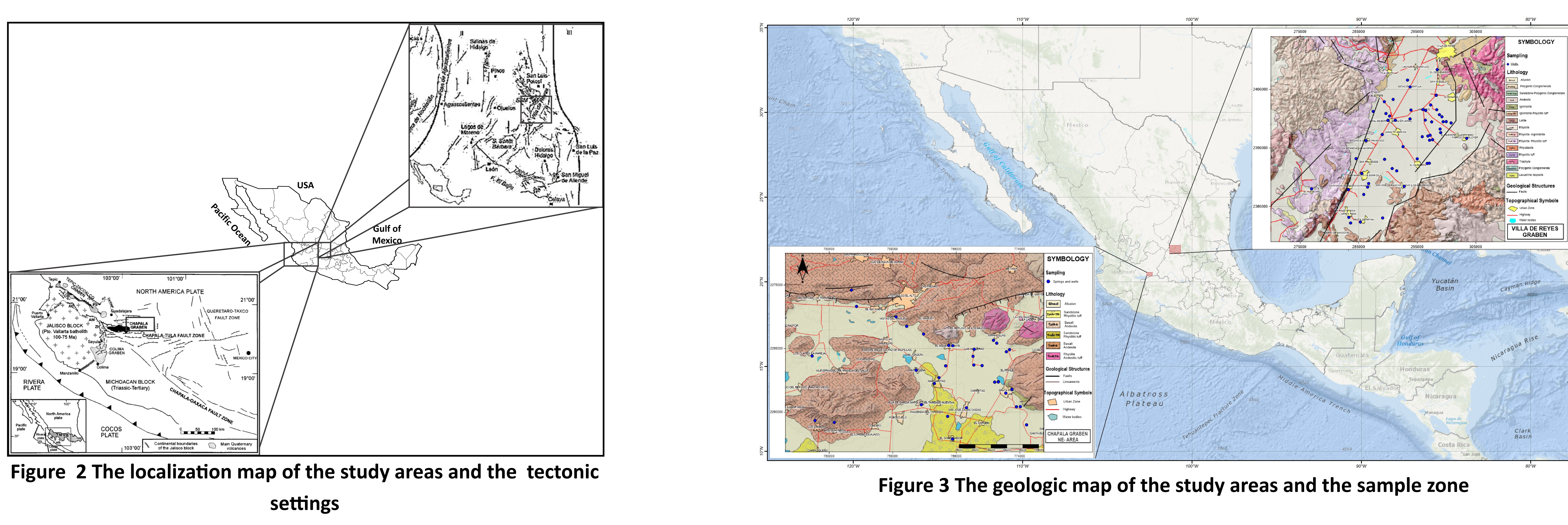

GEOLOGICAL SETTINGS:

The study areas are located in the central-north and central-western part of Mexico (fig. 2). The Chapala graben is located in the western part of the physiographic province of the Trans-Mexican Volcance zone of blocks with a displacement of more than $1000 \mathrm{~m}$ representing a greala basin in which a sequence of Miocene basalts and lacustrine sediments is found (fig. 3).
Elguera and Urrutia ficugauchi (1998) denominate as the Paleolake in the chapala

The Villa de Reyes graben is I ocated between the NE boundary of the state of Guanajuato and the state of San Luis Potosi ISLP. This is part of a sernes of tectonic structures present in the physiograph

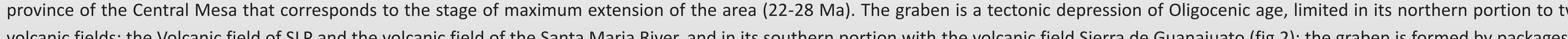
dacites to rhyolites of 32 at $28 \mathrm{My}$. The bottom of the basin is formed by exogenous domes of the Latita Portezuelos of $30.6 \mathrm{My}$ with a basement of late Cretaceous marine sediments, this is filled by riodacite rock Llopez-Loera, Tristan Gonzzalez, 2013.

RESULTS:

Chemical characteristic of water

Geothermometers
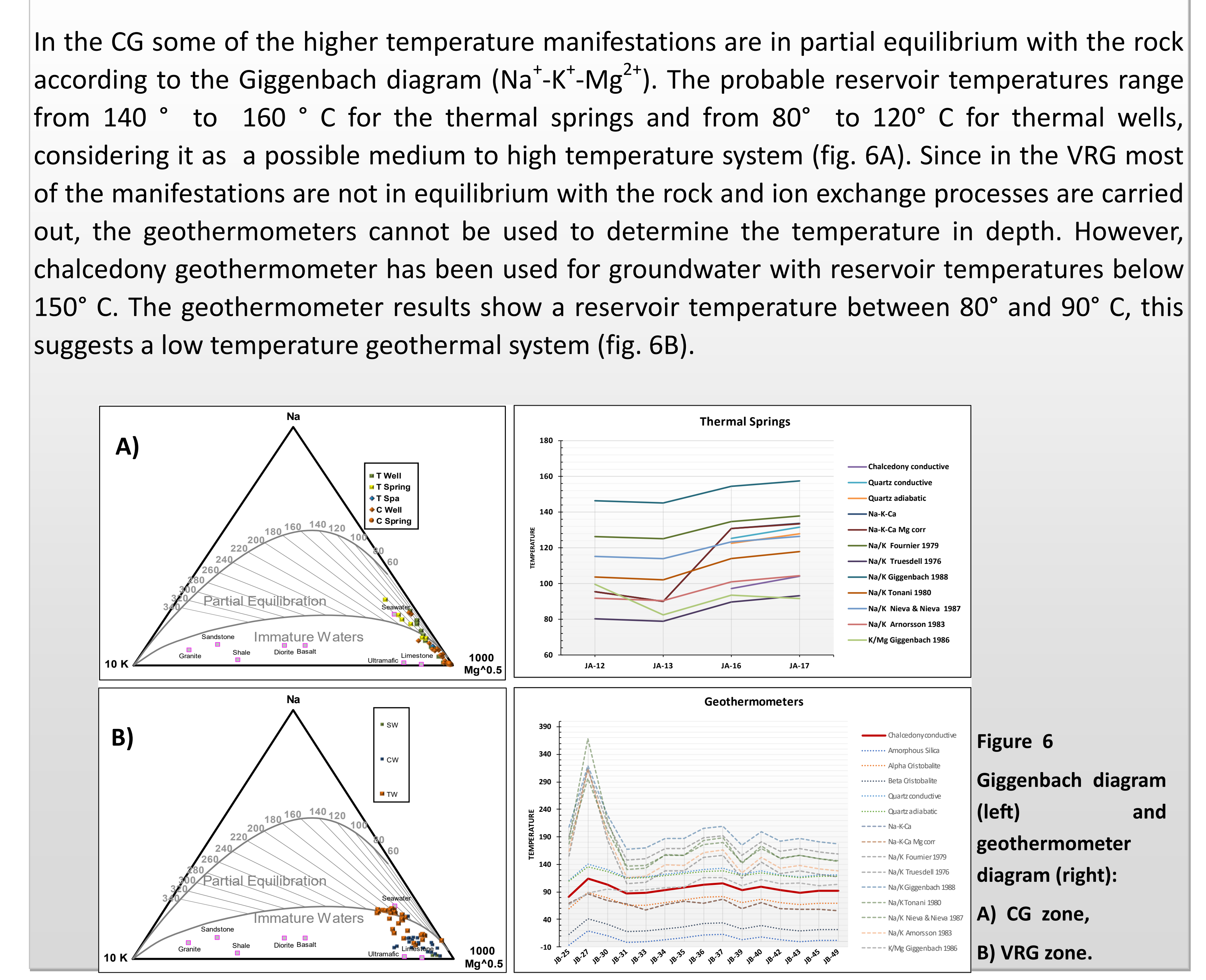

Stable Isotopes

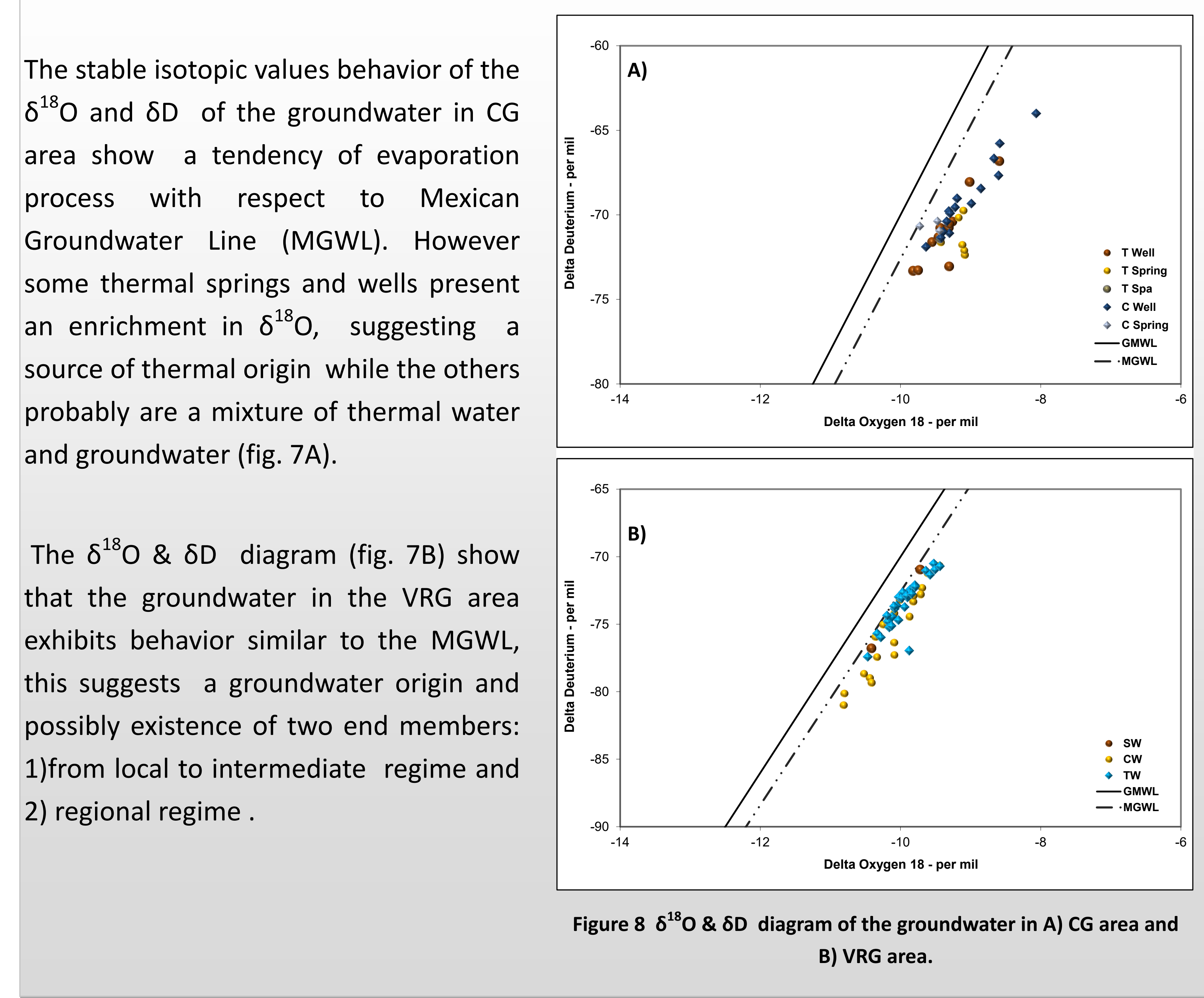

METHODOLOGY:

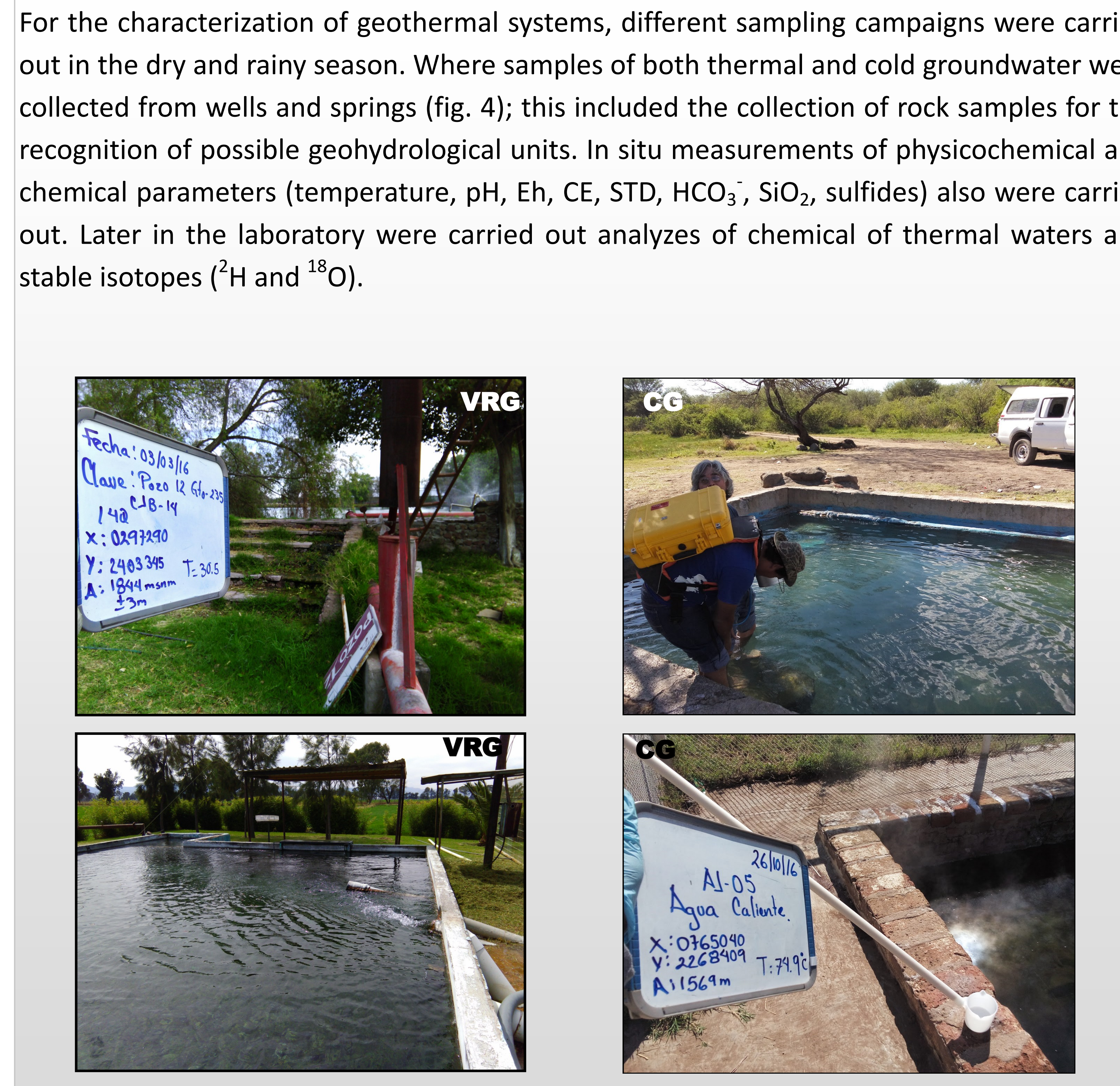

Fure 4 Sampling pictures in the study areas.

Thermalism and geologic context

The higher temperature hydrothermal manifestations in the CG present an NW-SE alignment
which may be temperature of the manifiestations decreasing towards SW of the study area and water flow
direction (fig. 8A). The highest temperatures in the VRG are in the limits of the basin aligned

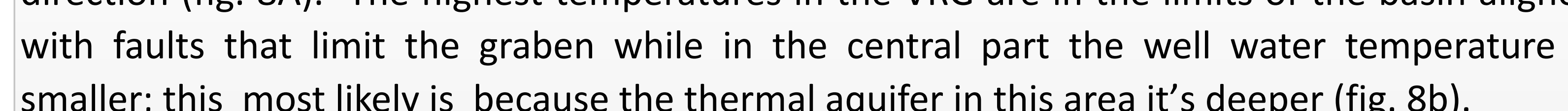

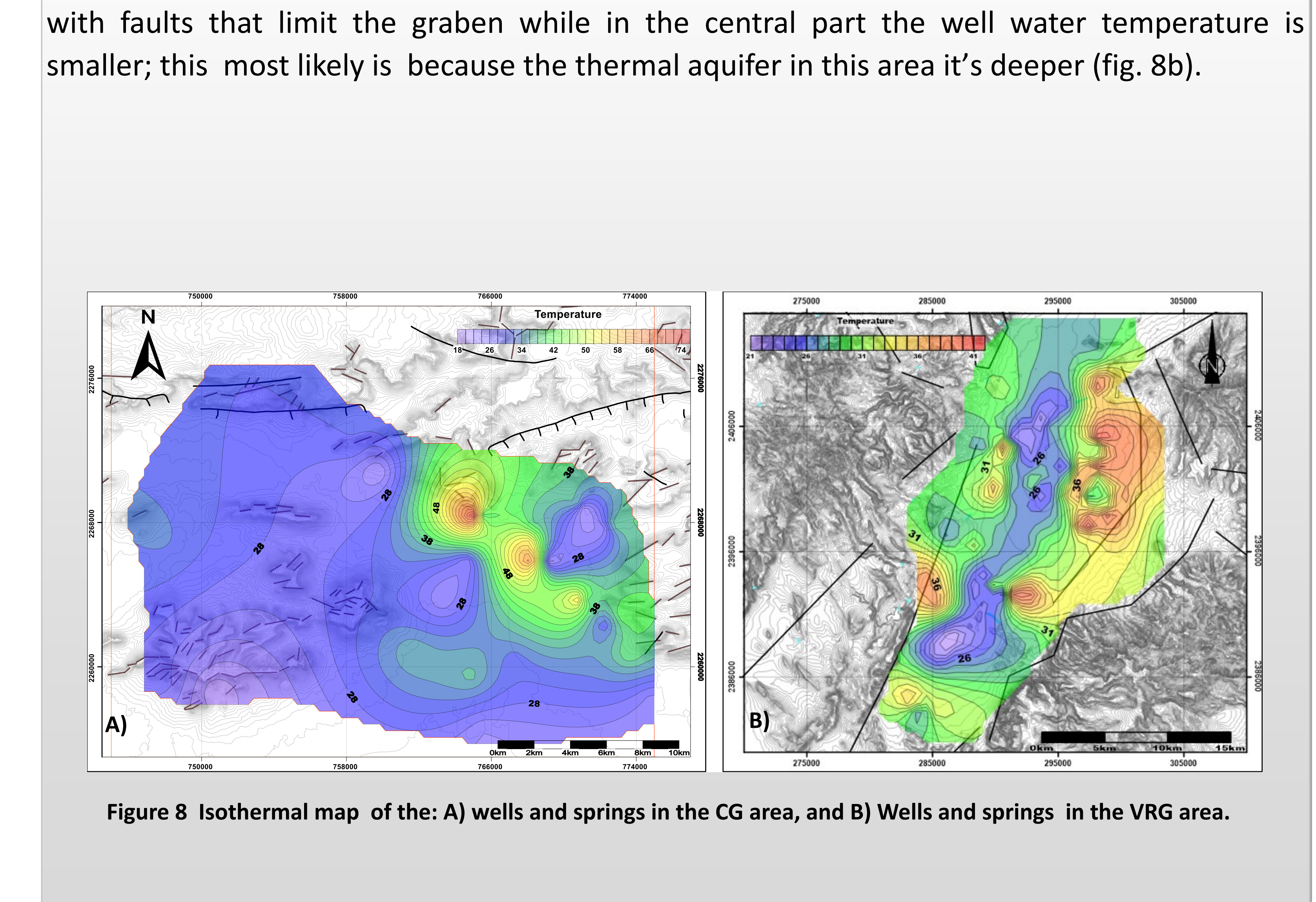

\section{CONCLUSIONS:}

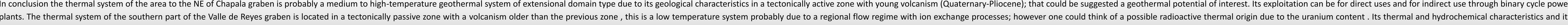

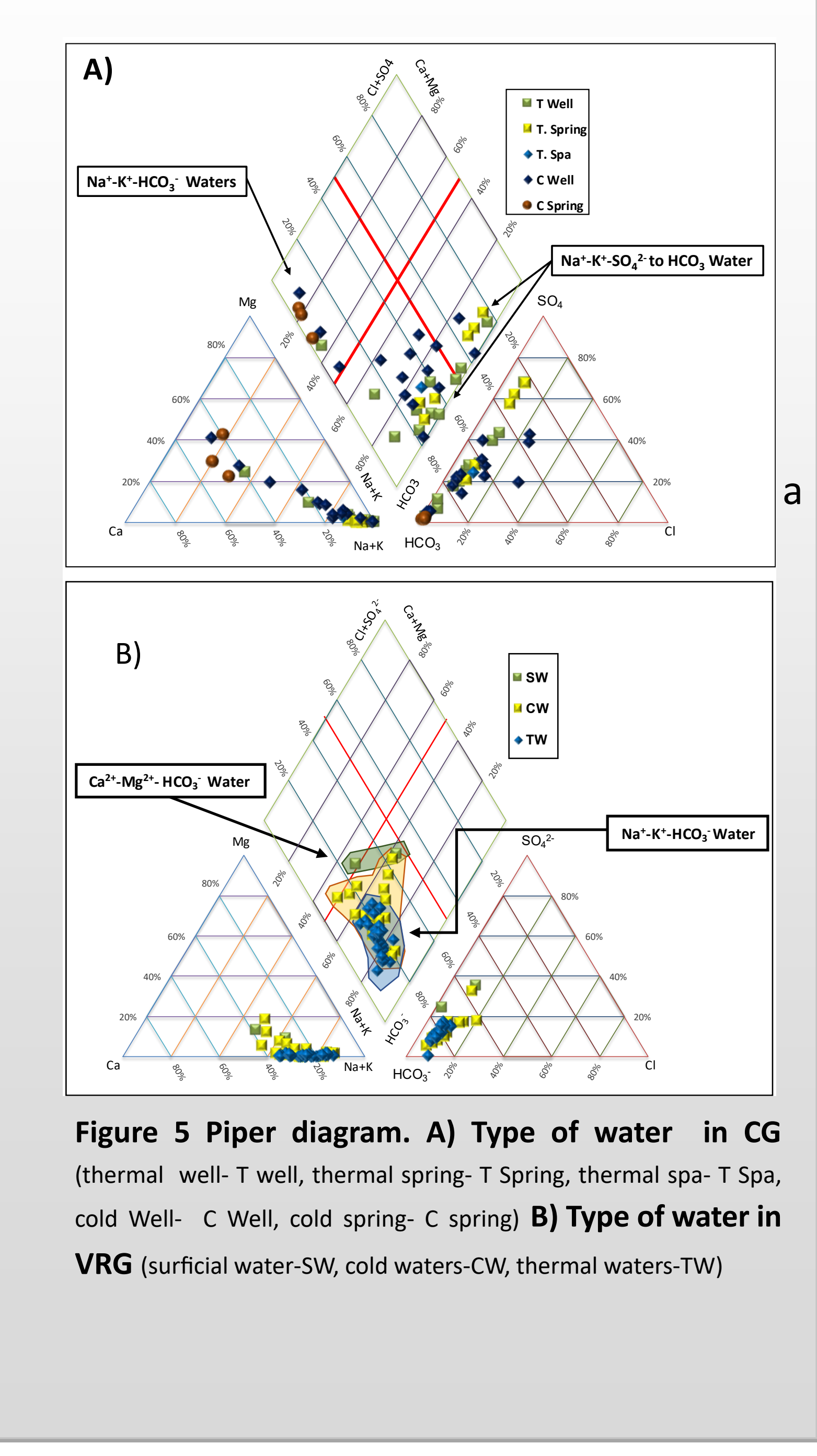

